\title{
Participation in Instrumental Music as a Predictor of Success in a Collegiate Level Aviation Flight Course
}

\author{
Tyson G. Jaquez \\ University of North Dakota
}

\begin{abstract}
Many different studies have been conducted that examine the effect that participation in instrumental music may have on the cognitive abilities and development of children and young adults. Many of these studies indicate that participating in instrumental music can enhance certain cognitive abilities. This study took those theories and applied them to collegiate flight training in an FAA FAR Part 141 training environment. Participants in the study were questioned about the extent of their participation in instrumental music. These results were then paired with their flight and academic records from their collegiate level private pilot flight course. Using varying statistical comparisons, specific measures of success in the private pilot course were measured against differing measures of participation in instrumental music. These tests revealed that, for most of the areas explored, there was not a significant difference between participants with experience in instrumental music and those that did not have any musical experience. However, statistical significance was found to correlate general participation in instrumental music and a reduction in the number of flight hours that were necessary to successfully complete the private pilot course $(t[66]=2.24, p<.05)$. In support of this finding, participants that had experience playing specifically the piano, demonstrated a significant reduction in the number of flight hours needed to successfully complete the private pilot course $(F[1,66]=4.158, p<.05)$. There appears to be some effect from participating in instrumental music on students in a collegiate level flight course; however, more study is warranted to discover the extent of these effects.
\end{abstract}

\section{Introduction}

Music education and the benefits that students who participate in it may gain have been a topic of debate in various educational forums within the United States. These benefits have been researched, debated, extolled, and denied. Many advocacy groups, such as the National Association for Music Education (NAFME), provide statistics and anecdotes that support the benefits of an educational program that includes music as a fundamental element (NAFME, 2012). However, these data only focus on how well students are prepared for college entrance exams such as the SAT. This study sought to take these anecdotal data a step further and find if there was a connection between participation in instrumental music and success in the real world application of aviation, specifically a university level private pilot course.

The argument about music has even worked its way into the current education debate on whether keeping music and arts in the public schools is important or not. Petress (2005) cites that music is beneficial to students by creating success in society, school, and developing intelligence as well as helping students to succeed in life. One of the most important questions that researchers ask today is "does music make you smarter?" 
Schellenberg (2005) answers "yes" to this question. While he states that music is not a fast solution for educational problems, it has been demonstrated that just listening to music can slightly enhance cognitive functioning over a short period of time.

Music has been linked to many different subjects in education. Participation in band (wind and percussion instruments) or orchestra (stringed instruments) has been shown to significantly increase students' scores on math proficiency tests, especially for low socioeconomic status (SES) students (Caterall, Chapleau, \& Iwanaga, 2009). Moreno (2009) discovered that that sensorimotor-auditory training, like that involved in learning an instrument, involves malleability, or brain plasticity within the auditory cortex. Moreno was also able to demonstrate that just six months of musical training was enough to modify behavior and brain function.

An instrumental music education has been demonstrated to have different effects on people based on the age at which they are exposed to it. Caufield (1999) posits that exposing young children to music, even before birth, may have the possibility of helping to create neural pathways in the auditory cortex of the brain. Creating these extra links has the possibility of setting children up for future cognitive benefits. Črnčec, Wilson, \& Prior (2006) discovered that participating in music lessons produced a small to medium effect on the spatiotemporal ability of younger children. Again, although these effects are small, they may lead to future gains in cognitive development.

In search of evidence that music does have an effect on cognitive development, scientists have begun to look at the brain itself. Hyde et al., (2009) demonstrated that there is a possible link between music and the development of the brain. The study shows that only fifteen months of musical training for children near the age of six created observable changes in their brains. Students that participated in music had significantly different brain deformation changes from those that did not participate in music. In addition, the study also found that students who participated in music for this same amount of time also showed a significant and near significant improvement in both the right and left hand fine motor skills, respectively.

In addition to the numerous studies demonstrating help in specific skills, it has also been demonstrated that participation in instrumental music can also help increase academic performance. Johnson and Memmott, in their 2006 study, found that students at the elementary school level that participated in "exemplary" music programs tended to score higher on both the English and Math portions of standardized tests. Schellenberg (2004) was also able to link IQ with participation in music. It was found that students who studied both the keyboard and voice lessons had small increases in their IQ over those that took drama lessons or did not participate in arts. In a 2009 study, Caterall, Chapleau and Iwanaga demonstrated that secondary school students who were highly involved in either band or orchestra outperformed their peers on math proficiency tests. In addition, Fitzpatrick (2006) demonstrated that, despite the differences found in test scores due to low socioeconomic status (SES), students that participated in, again, either band or orchestra performed better on standardized tests than peers not involved in music. 
Pilot selection has always been an important area of study throughout the history of aviation (Hunter \& Burke, 2002). Many different ways of determining the likelihood of success as a pilot have been used such as personality (Luuk, Luuk, and Aluoja, 2009), training scenarios (Bartram \& Baxter, 1996), and various other tests that examine motor skills and comprehension (Burke, Hobson, \& Linksy, 1997). Many of these methods focus on areas that music may help to enhance. Music has been shown to enhance not only cognitive development and abilities, but may also help to increase fine motor skills, which may eventually lead to better pilots.

\section{Research Methodology}

The author of this study conducted this research at the University of North Dakota (UND) in Grand Forks, ND. The John D. Odegard School of Aerospace Sciences at UND offers several degrees in aviation, with the Bachelor of Commercial Aviation focusing on flight training in a FAR Part 141 flight school. This program includes both collegiate courses and FAA approved flight and ground courses.

Due to the lack of research correlating music and successful pilot training, this study was exploratory in nature and sought to establish a possible connection between participation in instrumental music and success in a private pilot course which may then lead to further research.

The following research questions were used in the study to provide a general framework:

1. Is there a relationship between participation in instrumental music during elementary/secondary school and success in a collegiate level private pilot course?

2. Is there a relationship between the amount of time spent studying instrumental music during elementary/secondary school and success in a collegiate level private pilot course?

3. Is there a relationship between the age at which the study of instrumental music began and success in a collegiate level private pilot course?

4. Is there a relationship between current participation in instrumental music and success in a collegiate level private pilot course?

5. Is there a relationship between studying and performing in a specific group of musical instruments and success in a collegiate level private pilot course?

\section{Participant Selection}

Participants in this study were all students enrolled in the Commercial Aviation program advanced flight courses at the University of North Dakota. The private pilot course is a prerequisite for each of these courses which are listed in Table 1. 
Table 1

Flight Courses Used in the Study

\begin{tabular}{cc}
\hline Course Number & Course Title \\
\hline Avit 325 & Multi-Engine Systems and Procedures \\
Avit 414 & CFI* Certification \\
Avit 415 & Instrument Flight Instructor \\
Avit 480 & Advanced Aircraft Operations \\
\hline
\end{tabular}

*Certified Flight Instructor

\section{Data Collection}

Permission was sought by the researcher to enter the classrooms of the professors that were teaching the ground portion of each of the above-mentioned classes. Once permission was obtained, the research project was presented to the students in the class who were then asked to voluntarily participate in the study.

Data collection consisted of two steps. In the first step of data collection, a survey covering the participant's history, or lack of history, of instrumental music participation in elementary school, secondary school, and university was created and used. This survey was reviewed by experts in both the aviation and music education fields to ensure proper validity. A comparable survey was not found during the initial literature review. The second step of data collection involved matching the participants' academic records for their private pilot course with their survey. This was done by using their student ID number to match the records with the survey. Once the data were matched, the student ID was removed to de-identify all data.

\section{Limits and Assumptions}

This study was conducted under many assumptions and limitations. It focused on the relationship between participation in instrumental music and success in a private pilot course at one university. Therefore, these results may not be generalizable to a wider population without further study. In addition, the researcher only examined students that were majoring in Commercial Aviation, excluding other majors to avoid any confounding factors. This study also looks at students who are seeking a four year degree toward a professional career in flight, so the results may differ from general aviation (GA) pilots.

During the study, the researcher assumed that the instruction received by each participant was equal in nature. All flight instructors at UND follow a prescribed syllabus as described by the university's FAA approved Training Course Outline. The researcher also assumed that weather and other various acts of nature out of human control will likely have affected students in a similar manner. Therefore, these areas were assumed to not have a significant effect on the results gained in this study. 


\section{Results}

Several different measures were used in the study to determine success in a private pilot course. These measures include the number of flight hours required to complete the private pilot course, the pass rate for each of the different stage checks, the grade that was received in the ground course, and the overall pass rate of the private pilot course. Each of these measures was selected because it measured a different area of measurable success or failure within the private pilot course.

The first measure, the number of flight hours the participants required to successfully complete the private pilot course, and thus earn a private pilot certificate, was selected to measure the actual number of hours that a student spent in flight. In this study, a lower number of flight hours needed to pass the FAA exam at the end of the course is considered more successful. Table 2 outlines the statistics of the flight hours for all participants in the study.

Table 2

Flight Hours Descriptive Statistics, $N=68$

\begin{tabular}{cc}
\hline Descriptive & Flight Hours \\
\hline Range & 45.7 \\
Minimum & 38.7 \\
Maximum & 84.4 \\
Mean & 58.3 \\
Standard Deviation & 10.5 \\
\hline
\end{tabular}

The second of the measures used to determine success in the private pilot course was the rate at which the participants passed the various stage checks on the first attempt. According to the UND flight syllabus, there are three different stage checks, or flight exams, the last of which is the FAA private pilot check ride. Each stage check is comprised of two parts: the oral examination and the flight portion or practical examination. Each stage check must be passed in order to continue with the private pilot course. Passing the stage check on the first attempt is seen as more successful than a participant that needed to do the stage check two or more times in order to pass. The pass rate of each stage check is displayed in Table 3.

The third measure used in determining the success in the private pilot course was the grade that the participant earned in the ground portion of the private pilot course. An " $\mathrm{A}$ " was considered the most successful while an "F" was considered not successful. This measure was selected to analyze the relationship to classroom learning and provide a different view of success in the course. These grades are displayed in Table 4.

The fourth and final measure used in this study to determine the success within a private pilot course was if the participant had to retake the full private pilot course in order to successfully complete it. This measure was chosen in order to view the effect 
that music has on the overall success in the course, not just specific areas of the course. These data are shown in Table 5.

Table 3

Stage Check Pass Rate

\begin{tabular}{ccc}
\hline Stage Check & Number Passed on First Attempt & Percent of Students \\
\hline Stage 13 Oral & 75 & 96.2 \\
Stage 13 Flight & 58 & 74.4 \\
Stage 24 Oral & 53 & 67.9 \\
Stage 24 Flight & 50 & 64.1 \\
Stage 28 Oral & 72 & 92.3 \\
Stage 28 Flight & 59 & 75.6 \\
\hline
\end{tabular}

Table 4

Grades Received in the Ground Course

\begin{tabular}{ccc}
\hline Grade & N & Percent of Students \\
\hline A & 28 & 35.9 \\
B & 27 & 34.6 \\
C & 17 & 21.8 \\
D & 1 & 1.3 \\
F & 5 & 6.4 \\
\hline Total & 78 & 100 \\
\hline
\end{tabular}

Table 5

Number of Re-Takes to Complete Private Pilot Course

\begin{tabular}{ccc}
\hline Needed to Retake & N & Percent of Students \\
\hline No & 71 & 91.0 \\
Yes & 7 & 9.0 \\
\hline Total & 78 & 100
\end{tabular}

The results of the study are broken down here by research question and then by the measure used to test that question. Each statistical test was selected based upon the nature of the variables that were being tested for correlations and the nature of the data. Pearson's $r$ correlations and Spearman's Rho correlations were used frequently when the data did not meet parametric assumptions for the normal tests that were indicated by the variables. All tests used a $p$ value of .05 to indicate significance. 
The first research question examined the relationship between participation in instrumental music and success in the private pilot course. It was found that the number of flight hours was significantly lower for those participants that had participated in instrumental music when compared to participants who were not involved in music. The results for the first research question are displayed in Table 6.

Table 6

Summary of Results for Question 1 - Involvement in Instrumental Music

\begin{tabular}{cccc}
\hline Dependent Variable & Test Used & Test Statistic & Value of $p$ \\
\hline Flight Hours & Independent t-test & $t(66)=2.24$ & $.021^{*}$ \\
Stage Check Failures & Pearson's $r$ & $r=-.17$ & .152 \\
Ground Course Grade & Pearson's $r$ & $r=.21$ & .069 \\
Retake of Course & Chi Square & $x^{2}(1)=1.33$ & .249 \\
\hline
\end{tabular}

* Results are significant at

the 05 level

The second research question examined the relationship between the amount of time, in years, spent studying instrumental music and the relationship this had to success in the private pilot course. No significant differences were noted for this question. The results are summarized in Table 7 . The third research question explored the relationship between the age at which the study of instrumental music began and the success that participants had in the private pilot course. As in the second research question, there were no significant results found during the analysis. Table 8 summarizes these results.

Table 7

Summary of Results for Question 2 - Number of Years Studying Music

\begin{tabular}{clcc}
\hline Dependent Variable & Test Used & Test Statistic & Value of $p$ \\
\hline Flight Hours & Spearman's Rho & $r_{s}=-.09$ & .448 \\
Stage Check Failures & Spearman's Rho & $r_{s}=-.11$ & .344 \\
Ground Course Grade & Spearman's Rho & $r_{s}=.10$ & .404 \\
Retake of Course & Spearman's Rho & $r_{s}=-.10$ & .378 \\
\hline
\end{tabular}

Table 8

Summary of Results for Question 3 - Age at Which Study of Music Began

\begin{tabular}{cccc}
\hline Dependent Variable & Test Used & Test Statistic & Value of $p$ \\
\hline Flight Hours & Spearman's Rho & $r_{s}=-.11$ & .456 \\
Stage Check Failures & Spearman's Rho & $r_{s}=-.08$ & .534 \\
Ground Course Grade & Spearman's Rho & $r_{s}=.06$ & .661 \\
Retake of Course & Spearman's Rho & $r_{s}=-.09$ & .516 \\
\hline
\end{tabular}


The relationship between participation in instrumental music and participation in instrumental music during the private pilot course was examined in the fourth research question. As in the previous two questions, no significant results were noted during the analysis. The results of the fourth research question are displayed in Table 9.

Table 9

Summary of Results for Question 4 - Concurrent Participation in Instrumental Music

\begin{tabular}{cccc}
\hline Dependent Variable & Test Used & Test Statistic & Value of $p$ \\
\hline Flight Hours & Independent t-test & $t(76)=.16$ & .877 \\
Stage Check Failures & Spearman's Rho & $r_{s}=-.13$ & .246 \\
Ground Course Grade & Spearman's Rho & $r_{s}=.02$ & .856 \\
Retake of Course & Independent t-test & $t(76)=-.89$ & .379 \\
\hline
\end{tabular}

The fifth research question explored the relationship between learning specific groups of instruments and success in the private pilot course. The various instruments learned by the participants were divided into Band instruments (all wind and percussion instruments), Piano, and Other instruments which covered the string family as well as various other instruments. It was discovered that participants who had learned the piano required significantly fewer hours to complete the private pilot course (see Table 11). All other groups were non-significant at the .05 level. However, the measure of the Ground Course Grade approached significance in the Band group, indicating a trend. These results are summarized in Tables 10, 11, and 12.

\section{Conclusions}

\section{Significant Results}

Two sets of results in the study were found to be significant. It was discovered that participants who were involved in instrumental music, for any amount of time, required significantly fewer flight hours to complete the private pilot course than participants who were never involved in music. This result demonstrates that there is a possible connection between learning music and success in a private pilot course. In addition, when the instruments were divided into groups, results revealed that participants who had learned the piano, specifically, required significantly fewer flight hours to complete the private pilot course than participants who either played other instruments or never participated in music.

These significant results seem to indicate that participation in instrumental music may indeed have effects on learning and thus on success in a private pilot course. Hyde et. al. (2009) indicated that music may enhance fine motor skills. It is possible that this transfers from musical instruments, particularly the piano, into the aircraft during flight 
training. It is also possible that the added brain plasticity, indicated by Moreno (2009), allows flight students who have participated in instrumental music to more easily absorb and understand the difficult concepts that are required during the flight portion of the private pilot course.

Table 10

Summary of Results for Question 5 - Band

\begin{tabular}{cccc}
\hline Dependent Variable & Test Used & Test Statistic & Value of $p$ \\
\hline \multicolumn{1}{c}{ Flight Hours } & One Way Independent & $\mathrm{F}(1,66)=2.192$ & .143 \\
& ANOVA & & \\
Stage Check Failures & Spearman's Rho & $r s=-.15$ & .191 \\
Ground Course Grade & Spearman's Rho & $r s=.22$ & .054 \\
\hline
\end{tabular}

Table 11

Summary of Results for Question 5 - Piano

\begin{tabular}{cccc}
\hline Dependent Variable & Test Used & Test Statistic & Value of $p$ \\
\hline Flight Hours & One Way Independent & $\mathrm{F}(1,66)=4.158$ & $.045^{*}$ \\
& ANOVA & & \\
Stage Check Failures & Spearman's Rho & $r s=-.81$ & .481 \\
Ground Course Grade & Spearman's Rho & $r s=.17$ & .133 \\
\hline
\end{tabular}

* Results are

significant at the 05

level

Table 12

Summary of Results for Question 5 - Other

\begin{tabular}{cccc}
\hline Dependent Variable & Test Used & Test Statistic & Value of $p$ \\
\hline Flight Hours & $\begin{array}{c}\text { One Way Independent } \\
\text { ANOVA }\end{array}$ & $\mathrm{F}(1,66)=.450$ & .505 \\
Stage Check Failures & Spearman's Rho & $r s=.15$ & .188 \\
Ground Course Grade & Spearman's Rho & $r s=.004$ & .971 \\
\hline
\end{tabular}

While these results indicate that there is some correlation between instrumental music training and success in a private pilot course, it is extremely difficult to see exactly where the correlation is. As mentioned above, the enhancements could come from increased practice of hand/eye coordination or from brain plasticity that leads to better learning. It would also appear that the piano is the instrument that is best suited to aviation students. However, at this time, it is not possible to tell why the piano seems to be the best instrument for these students. While these significant results are promising, more study 
is needed to find which activities and brain processes are enhanced or affected by participation in instrumental music.

\section{Non-Significant Results}

Although not statistically significant, the other results from this study lead to more questions in this area of research. When the ground course grade was compared to involvement in instrumental music, a positive correlation was discovered. Although this result was not found to be significant, it does appear that a small trend may be present in the data. It is possible that future studies may find significance with a different and larger sample.

The other areas examined in the first research question displayed very low correlations between participation in instrumental music and the stage check pass rate, and the need to retake the course. This seems to indicate that there is not a noticeable connection between these areas and succeeding in a private pilot course. This result was rather surprising, considering much of the research done with music education shows that music enhances grades and performance in school and on standardized tests.

The lack of significance in any of the measurements for the second research question bring up some interesting questions. It can be expected that the longer a person studies music, the larger the benefits they may receive from that study. However, this does not appear to be the case when it comes to taking a private pilot course. On the other hand, these results tend to support the theory that music either does not have the effects on mental ability that some studies claim (Črnčec, Wilson, and Prior, 2006) or, if there are benefits gained, they are short lived and do not carry on beyond the time of study (CostaGiomi, 1999). A future study may look at a possible correlation between the length of time that passes between the completion of music study and the beginning of the private pilot course for any clues into these surprising data.

The third research question also demonstrated non-significant results for all measurements of success in a private pilot course. Studies such as the one conducted by Rauscher et al. (1997) indicate that the younger a person is when they begin to study music, the more pronounced the effects of the music on brain plasticity. However, the non-significant results from this section indicate that this is not the case, at least in the field of aviation. It is possible that any benefits that are gained from music may come from practice that is not age dependent, indicating that the study of music can begin at any age, and that there is not an optimal age at which to begin.

The fourth research question also demonstrated non-significant results. Within this fourth area of research, it may have been surmised that if past participation benefited the participant, then someone who was still participating in music might have larger benefits. This was not the case, however, based upon the results that were derived from this area. Again, these non-significant results point to the fact that there seems to be a limit to the amount of help that a person can glean from their music education. 
The fifth research question, with the exception of the piano group, again showed nonsignificant results. This demonstrates that people who play piano may have an advantage over those that play other instruments when it comes to aviation. However, it was surprising to find that only one group, the piano players, may gain any benefits in aviation from their participation in instrumental music. Many different instrument groups must use coordination, in different forms, to perform music on their instruments. However, the significant and non-significant results from this study would seem to indicate that playing the piano has the best correlation to the types of coordination that are needed on the flight deck. Future studies may be completed to study the exact correlations and their possible ramifications on future pilots.

Overall, it can be concluded from this research that instrumental music does have some positive effects on students who are in a collegiate level aviation flight course. However, from the abundance of non-significant results, it also appears that participation in instrumental music does not have the large effect that would be expected based on the studies done of the effects of music on standardized tests and the studies conducted in actual classrooms. For the group tested in this research, it appears that piano players are reaping the greatest benefits of their instrumental music education.

There are many areas this study has opened for further research, and indeed more research is warranted. This study was limited to a small group of students at only one university flight school. A broader study that included many more students and university flight programs across the country would help to create a clearer picture of the effects that an instrumental music education has on students enrolled in collegiate flight programs. Another area that could be examined is different groups or kinds of music. An example of this would be to include vocal music participation in the study. This study focused solely on instrumental music. Also, a larger sample might yield more variety of instruments. With this, a broader comparison between types of instruments could be made to more clearly answer the fifth research question.

The results of this study have shown that there are some interesting connections between instrumental music and success in a collegiate level aviation flight course. However, the study also opened up many areas for future research and created more questions than it answered. Most of the results that were expected were not found to be true for the UND private pilot students; however, other places and groups may show different results. This study has hopefully created a starting place for future research with music education and its relation to the field of aviation. It also opens the question of whether there are any unrelated fields that may have a positive impact on aviation education, and therefore may be a benefit to future aviation students. The boundaries and connections have been tested. Some were broken, and others were not. However, it is the question that leads points to the potential for further research. 


\section{References}

Bartram, D., \& Baxter, P. (1996). Validation of the Cathay Pacific Airways pilot selection program. International Journal of Aviation Psychology, 6(2), 149.

Burke, E., Hobson, C., \& Linsky, C. (1997). Large sample validations of three general predictors of pilot training success. International Journal of Aviation Psychology, $7(3), 225$.

Caterall, J. S., Chapleau, R., \& Iwanaga, J. (1999). Involvement in the arts and human development: General involvement in intensive involvement in music and theatre arts. The Imagination Project at UCLA. University of California at Los Angeles. Retrieved from: http://www.newschool.ie/_fileupload/Image/artsinvolvement.pdf

Caufield, R. (1999). Mozart effect: Sound beginnings? Early Childhood Education Journal, 27(2), 119-121.

Costa-Giomi, E. (1999). The effects of three years of piano instruction on children's cognitive development. Journal of Research in Music Education, 47, 198-212. doi: $10.2307 / 3345779$

Črnčec, R., Wilson, S., \& Prior, M. (2006). The cognitive and academic benefits of music to children: Facts and fiction. Educational Psychology, 26(4), 579-594. doi:10.1080/01443410500342542

Fitzpatrick, K. R. (2006). The effect of instrumental music participation and socioeconomic status on Ohio fourth-, sixth-, and ninth-grade proficiency test performance. Journal of Research in Music Education, 54(1), 73-84.

Hunter, D. R., \& Burke, E. F. (1994). Predicting aircraft pilot- training success: A metaanalysis of published research. International Journal of Aviation Psychology, 4(4), 297.

Hyde, K. L., Lerch, J., Norton, A., Forgeard, M., Winner, E., Evans, A. C., \& Schlaug, G. (2009). Musical training shapes structural brain development. The Journal of Neuroscience, 29(10), 3019-3025. doi:10.1523/JNEUROSCI.5118-08.2009

Johnson, C. M., \& Memmott, J. E. (2006). Examination of relationships between participation in school music programs of differing quality and standardized test results. Journal of Research in Music Education, 54(4), 293-307.

Luuk, K., Luuk, A., \& Aluoja, A. (2009). Predicting professional success of air traffic control personnel from their personality profile at admission to ab initio training. International Journal of Aviation Psychology, 19(3), 235-251. doi:10.1080/10508410902983896 
Moreno, S. (2009). Can music influence language and cognition? Contemporary Music Review, 28(3), 329-345. doi:10.1080/07494460903404410

National Association for Music Education. (2012). Support music: Make your case. Retrieved from www.nafme.org/supportmusic_cases. Reston, VA.

Petress, K. (2005). The importance of music education. Education, 126(1), 112-115.

Rauscher, F. H., Shaw, G. L., Levine, L. J., Wright, E. L., Dennis, W. R., Newcomb, R. L. (1997). Music training causes long-term enhancement of preschool children's spatial-temporal reasoning. Neurological Research, 19, 2-8.

Schellenberg, E. G. (2004). Music lessons enhance IQ. Psychological Science (WileyBlackwell), 15(8), 511-514. doi:10.1111/j.0956-7976.2004.00711.x

Schellenberg, E. G. (2005). Music and cognitive abilities. Current Directions in Psychological Science (Wiley-Blackwell), 14(6), 317-320. doi:10.1111/j.09637214.2005.00389.x 